dykes radiate from the lake, cutting through the older lavas as exposed on the inner slope. The inner slope appears to have been formed by fracture, and not by flow. The old crater did not occupy the whole extent of the present caldera; if it had done so the lava would have overflowed at the lowest part of the rim, but the whole rim is formed of lava-flows from some higher and now vanished centre. One very remarkable feature of the geology is the strong glaciation of the rim, shown by wellmarked striæ and great morainic deposits. There are traces of glaciers radiating down the slope, in some cases to a distance of five miles. There is evidence of volcanic activity during the glacial period; on one of the peaks of the rim an iceplaned surface of old lava is covered by two layers of pumice separated by a flow of rhyolite. The severe floods, which must have accompanied eruptions at that period, would account for the vast masses of sediments which fill the radiating valleys. The observed phenomena can only be accounted for by the presence of a great volcanic peak covering the present area of the lake, and sweeping upward as a continuation of the present outer slopes. The probable history of this mountain is summarised thus:-

The history of Crater Lake and its rim began in the upbuilding, by normal volcanic processes, of a large volcano-to which the name Mount Mazama is given-comparable in the nature of its lavas and in its structure and size with the greater peaks of the Cascade Range. This volcano was active in the

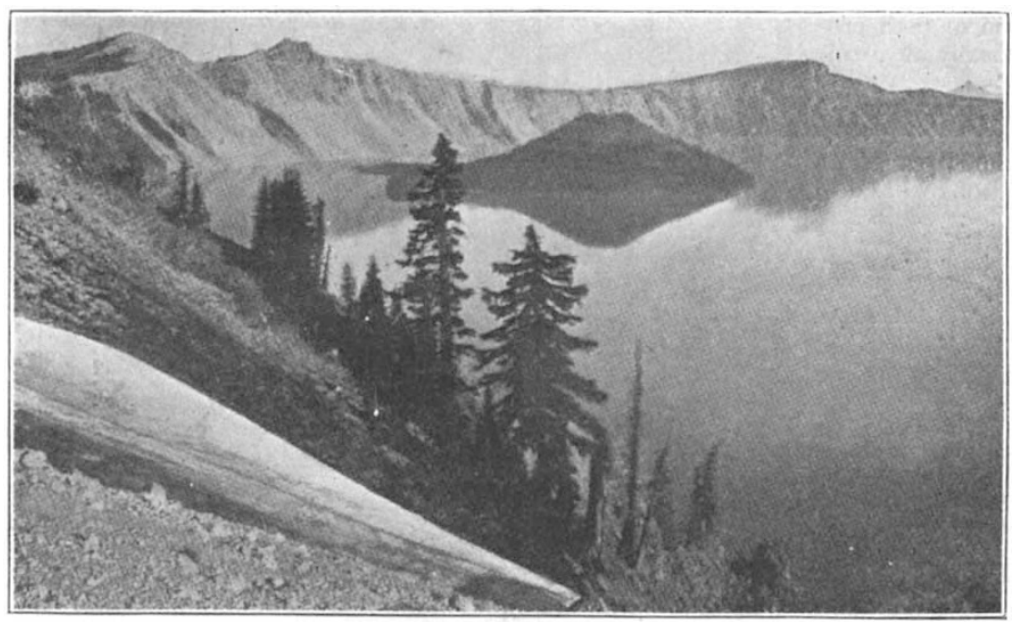

FIG. 2.-Crater Lake, showing Wizard Island.

glacial period, lava and glaciers combining to mould its form. Somewhere near its final eruption, and perhaps in consequence of the rapid draining away of lava by the small cones near the base of the mountain, the molten material from the interior was withdrawn, the summit of Mount Mazama collapsed and sank away, leaving a huge gulf measuring six miles by four, and about 4000 feet deep. Volcanic activity continued on the floor of the caldera for some time ; but since rainfall is in excess of evaporation in that region, water gradually accumulated to form the present Crater Lake.

The water of the lake is remarkably transparent, free from any visible organic matter, and fresh to the taste, but no analysis of its saline contents seems to have been made. The temperature of the water when examined in August 1896, averaged about $60^{\circ} \mathrm{F}$. on the surface. The deep-temperature, taken by means of a Negretti and Zambra reversing thermometer in the unsatisfactory Magnaghi frame, was reported as $39^{\circ}$ at 555 feet, $4 \mathrm{I}^{\circ}$ at 1040 feet, and $46^{\circ}$ at 1623 feet. If these figures were trustworthy, it would appear that the water in Crater Lake still derives heat from the rocks ; but if this interpretation is correct, it is difficult to account for the minimum at the maximum density point, unless indeed the water is saline enough to have a maximum density point perceptibly lower than that of fresh water. Dr. Evermann, of the U.S. Fish Commission, who made the observations, does not seem to have entire confidence in their accuracy.

Only three species of invertebrates were found living within No. 1477 , voL. 57$]$ the rim of Crater Lake-a frog, a snake, and a salamander. By the use of tow-nets several minute alga were found in the water, and many minute crustacea, of which Daphnis pulex pulicaria was the commonest. Several larval insects, a leech, a species of Gordius, and one species of mollusc, an undetermined Physa, were also found. No fish could be discovered, but an attempt to introduce trout is to be made.

Dr. Merriam gives an elaborate classification of the life-zones on Mount Mazama, and a complete list of all the animals found; an extensive flora is also published, and in all respects the special number of Mazama is highly creditable to the Society which has produced it. The Mazamas are to popularise the lake for the use of tourists by introducing various attractions, which we fear will detract from its present charm by destroying the absolute wildness of the whole surroundings.

H. R. M.

\section{ADDRESS TO THE ROYAL ASTRONOMICAL SOCIETY.}

I $\mathrm{T}$ is the duty of your President at this annual meeting of our Society to address you on a very important subject. I allude, of course, to the award of the Gold Medal which is annually conferred by the Royal Astronomical Society on some astronomer who has rendered signal service to our science. The discharge of that duty is, perhaps, the most responsible official act which devolves on the occupant of this chair during his tenure of the distinguished position of President. I am to set forth the ground upon which on the present occasion the medal has been awarded by your Council to our distinguished Fellow, Mr. W. F. Denning.

The contributions of Mr. Denning to astronomy may be ranged under three heads.

(I) Discovery of Comets.

(2) Observation of Planetary Phenomena.

(3) Researches on Meteors.

It will be convenient for me to describe his work in these three different departments in the order just given. The first and second departments must, however, be treated with comparative brevity, for it is on the third department that your Council laid special stress in making their award.

\section{(1) Come'ss.}

Each year usually brings the announcement of certain new comets, the discovery of such objects being the rewards of those observers who patiently scan the heavens, evening after evening and morning after morning, with the particular object of detecting these shy visitors to our skies. Mr. Denning has been one of those who have engaged in this work, and his success has been noteworthy. The following list gives the designations of five comets which have been discovered by our medallist.

Comet I 881 V. Period, $8 \cdot 68$ years.

Comet 1890 VI.

Comet I89I I.

Comet I892 II.

Comet I894 I. Period, 7.3 years.

While searching the skies for comets, Mr. Denning has not unfrequently discovered nebulæ which had escaped the attention of previous observers. No fewer than twenty new nebula have thus been added by Mr. Denning to the lists of those already known. Most of these new objects lie in the vicinity of the North Pole.

\section{(2) Planetary Observations.}

A striking characteristic of Mr. Denning's work is the methodical accuracy with which he has carried through whatever astronomical restarch he has in hand. Mr. Denning never spared himself any pains in the efforts necessary to give his work the inestimable charms of thoroughness and precision. This may well be illustrated by his planetary observations. We here

1 Delivered on February in by the President, Sir Robert Ball, on the occasion of the presentation of the Gold Medal to Mr. W. F. Denning. 
specially refer to his work on Jupiter. It is well known that this very difficult object not only demands instruments of much optical perfection, but also calls for the exercise of the highest qualities which constitute a consummate astronomical observer. Mr. Denning, using a $10_{4}^{1}$-inch reflector by Browning, made admirable sketches of the planet, in which he represented a remarkable amount of detail with a skilful pencil. But he was not content with work of this kind merely, however valuable such work may be. He watched the revolutions of a large number of spots individually, and determined as accurately as possible their times of transit over the central meridian of the planet. By such observations he ascertained the period of rotation of a large number of the most notable spots. Thus he illustrated the very interesting fact that the individual spots were animated by large proper motions on the surface of the planet. The famous red spot, so well known to every astronomer, has been in particular most diligently followed by Mr. Denning, and he has demonstrated the remarkable circumstance that its period of rotation varies from year to year. The results at which he has thus arrived are in close accordance with the observations of other accomplished astronomers.

\section{(3) Researches on Meteors.}

But the great work of Mr. Denning's scientific career, and that which has been mainly instrumental in deciding your Council to confer on him the distinction of the Gold Medal, has been connected with the very interesting subject of luminous meteors. The labours of Mr. Denning have been extensive enough to cover nearly every branch of the subject of meteoric astronomy. It would be difficult, indeed I may say it would be impossible, to render any adequate account of it within the limits of an address. I am, therefore, obliged to restrict myself to those more salient points. which have specially been under the consideration of your Council.

The papers on luminous meteors communicated to the Royal Astronomical Society by Mr. Denning, and printed in the Monthly Notices, number altogether forty-two. In bulk they would, if collected together, constitute two-thirds of an ordinary annual volume in that form of the Society's publications. These papers are illustrated much more copiously than has usually been the custom with graphic and instructive figures.

A considerable number of these memoirs contain valuable lists of meteoric radiants derived either exclusively from $\mathrm{Mr}$. Denning's own work at Bristol, or from his own observations in comparison with the work of other astronomers in the same field.

Mr. Denning's first published list of radiants appeared in 1876 . It contains the determinations of twenty-seven radiant points, derived from his own observations of nearly 900 meteor tracks which he had himself mapped at Bristol between $187 \mathrm{I}-76$. In this early list the periods of the recurrence of the showers are occasionally indicated by single days or short periods. But usually the month of recurrence is alone given. The list contains careful determinations of the radiant-points of the chief annual showers, such as Quarantids in 1873 , the Lyrids in 1873 and 1874 , the Perseids in 1871 and 1874 , the Orionids in 1874 , and the Andromedids in 1872. It is interesting to note that showers were found in correspondence with all but four radiants in the list contained in Mr. Greg's first general Star Shower Catalogue. This was published in comparison with Dr. Heis' similar list of the same year in the British Association volume of Reports for the year I874. The four radiants which Mr. Denning was not able to corroborate are, it ought to be observed, marked as doubtful by Mr. Greg.

The latest list of radiants which has been issued by $\mathrm{Mr}$. Denning, and the longest paper that he has as yet commmuni cated to the Monthly Notices, was published in I890. This important work gives remarkable evidence of the unflagging dilligence of our medallist. It contains a list of nine hundred and eighteen radiant points, deduced from the observations of no fewer than 9177 meteors, mapped at Bristol, between the years I873 and I889. This list, it should be remarked, includes repeated observations of the same radiants. This is the case not only with regard to the chief showers, but also with regard to various minor showers, whose yearly dates of recurrence cannot in the present state of our knowledge be assigned with any certainty.

Though many of these showers are but sparsely characterised by meteors, or, to use the more technical expression, are showers of great tenuity, they have not escaped the diligent scrutiny of our medallist. In such cases the dates are generally assigned to the single days when they have had apparently a maximum abundance. A column of supplementary dates have been added, which seldom range over more than a week. It will thus be seen that this catalogue presents an extensive series, not so much of averaged results as of exact and valuable individual determinations.

In other papers by Mr. Denning, mean results have been given which may be regarded as expressing, with regard to many important showers, the present state of our knowledge. For the chief meteoric showers a list of this kind was published in 1887. In it will be found mean positions for 1880 , derived from fifteen years of observations of the radiant-points of the nine chief yearly showers. These contain the seven well-known periodic swarms of January, April, August, October, November (two showers) and December, adding to these the striking and very regularly visible displays of May 6 and July 28 .

The most important contributions which our medallist has made to the general problems connected with luminous meteors are connected with the long duration of certain meteoric radiants. The fact of long persistency of radiant-points, and of close assemblages about the points of groups or conpact families of simultaneous or successive meteor streams, is as old as Heis' first essays in meteor showers. It is, however, to Mr. Denning's persistent inquiries that we are mainly indebted for our knowledge of this subject. In his important paper of December 1884, Mr. Denning writes: "The fact of stationary radiants exhibiting visible activity during several months is a phenomenon so unaccountable and so utterly opposed to the approved theories as to the orbits of shooting stars, that it must receive a most crucial examination before it can be accepted."

The long-continued labours of Mr. Denning on this important subject have demonstrated the existence of these enduring radiants. The theoretical difficulties connected with the subject may be still not. altogether removed, but we can hardly refuse assent to Mr. Denning's words when he says: "It must be conceived that a well-attested fact of observation, however hard to reconcile with known theories, ought on no account to be dis. regarded on account of its nonconformity."

It is, of course, known that the Perseids from the August shower are found, not only on the special nights with which the swarm is chiefly associated, but they are also displayed on many preceding and following nights. Mr. Denning has traced meteors of this group for the twenty-six nights from July 25 to August I9, and their radiant advanced in that interval over a distance of 40 degrees. In one of those admirable diagrams by which the interest of Mr. Denning's papers is so greatly increased, he gives a curve of the ordinary number of Perseids from one on July 25 to a maximum of 57 on August 10 , and then declining to I on August 19. In his paper of $1890 \mathrm{Mr}$. Denning shows that the range of the Perseids is even wider still. I cite this case of the Perseids, because the gradual shift of the radiants as days and weeks passed by is, of course, no more than should be expected from the change of the place of the earth in its orbit. The extraordinary fact is that in the case of certain other showers, which are visible for weeks or months, the radiant undergoes no appreciable change in position. Mr. Denning selected for discussion in his "Memoir" of I884 six special showers. Among these we may particularly note the $\alpha-\beta$ Perseids, which show a constant radiant from July 6 to November 30.

Such a paper as that to which I am now referring must be regarded as a classic which every one who is interested in the fascinating subject of meteors would do well to study. It is full of interesting facts and suggestions. We learn that in the catalogues published up to this date there are no fewer than 2 IOO radiants resulting from the projected paths of upwards of 6200 meteors ; many of these are, however, duplicate observations of identical showers, and Mr. Denning adds that he does not believe the total number of well-defined streams would exceed 350 .

In his introduction to the great catalogue of $1890, \mathrm{Mr}$. Denning has given a statement of his methods of work.

"My plan of work may be briefly described as follows. All the observations were made in the open air and from the garden adjoining the house. Attention was almost invariably given to the eastern sky. In mild weather I sat in a chair with the back inclined at a suitable angle, but on cold frosty nights I found it expedient to maintain a standing posture and some-

$$
\text { No. I } 477 \text {, voL. } 57 \text { ! }
$$


times to pace to and fro, always, however, keeping the eyes directed towards the firmament in quest of meteors."

Our medallist has recently published in the Observatory an instructive and opportune series of papers on the great showers of Leonids which may reasonably be expected in the next year or two. This subject is here discussed with characteristic wealth of knowledge and experience. He commences with the remark: "It may be safely said that in the month of November during the next few years, all astronomers and a large majority of the general public will becrme meteoric observers, for the phenomena presented will be of an exceptional kind and of a character to interest every one."

We all echo these words. I think $\mathrm{I}$ am justified in adding that much of the recently awakened interest in the subject has been due to the worthy example Mr. Denning has himself given us. Which of us would not be proud to emulate his singlehearted and enthusiastic devotion to the discovery of truth in this beautiful department of astronomy?

It is a matter of great regret to every one here assembled that our medallist, whom we greatly wish to honour, is not now present to accept in person our award. We regret this all the more when we learn that ill-health is the cause of his absence. We all join in a hearty wish for his speedy recovery, and in the hope that he may shortly be able to resume those observations which we receive with such interest and pleasure. We desire to assure him not only of our appreciation of his admirable work, but of the high esteem which we entertain for the spirit in which that work has been conducted.

On your behalf, therefore, I now hand the Gold Medal of the Royal Astronomical Society to our Secretary, to be by him transmitted to Mr. W. F. Denning in recognition of the valuable services to our science he has rendered, especially in the department of meteoric astronomy.

\section{HISTORY AND OBJECTS OF THE PHYSICAL SOCIETY.}

I PROPOSE on this occasion to begin with a few words on the history and objects of our Society, and afterwards to glance briefly at the principal events of physical interest which have occurred during the past year.

The Physical Society was founded in 1874 , and owed its origin mainly to the initiative of the late Prof. Guthrie. From the first years of its existence up to the present time it has included among its members nearly all the leading physicists of the United Kingdom.

In the early days our meetings were, by permission of the Lords of the Committee of Council on Education, held in the Physics lecture-room of the Royal College of Science at three o'clock on Saturday afternoons, members being allowed the free use of the laboratory apparatus for the illustration of their papers. The proceedings were at that time rather less formal than is customary at present. The papers were rarely, if ever "referred" before being read; often, indeed, they were read long before they were actually written, while a large proportion of the communications were of a purely oral character, and never intended for publication at all, except perhaps in the short notes which the reporter sent to the scientific journals. Special prominence was given to experimental demonstrations illustrative not only of original researches, but also of such work carried on outside the Society as happened to be attracting attention at the time. . .

Under the somewhat lax régime which then prevailed, it necessarily happened that the communications made to the Society were not always of a very high order of merit. . . But from the very beginning the Council has always been carefu not to print in the Proceedings anything that was not of sound scientific value, and while the number of important papers that have been published through the medium of the Physical Society is large, very little of doubtful quality has found a place in the Journal.

The first material change in our routine took place in the year I889, when the day and hour of meeting were altered from Saturday afternoon at three to Friday at five o'clock. . . . I may here mention that the Council has more than once con sidered whether it might not be expedient to hold our meetings in the evening. Many, no doubt, would consider this prefer-

1 Presidential Address to the Physical Society. (Abstract.) February II By Shelford Bidwell, F.R.S. able, but the balance of convenience appears to be clearly in favour of the afternoon.

During the South Kensington epoch the Physical Society published ard presented to its members a number of valuable books, including, among others, Prof. Everett's well-known treatise on the C.G.S. system of units and the works of Wheatstone and of Joule. It also issued twelve volumes of Proceedings, in which were collected such of the communications to the Society as had been approved for publication. By an arrangement with the proprietors of the Philosophical Magazine the same papers were also (as now) printed in that journal, being thus, to the author's great advantage, assured of a wide circulation throughout the scientific world. In the same period, notwithstanding the small amount of the annual subscription paid by members and of the composition fee for life membership, the Society's income so far exceeded its expenditure that it was able to accu. mulate and invest a capital of nearly $3000 \%$

When the Society entered upon its twenty-first year with a position which, if somewhat unpretending, was well recognised and firmly established, it was felt that the time had come when, in the interests of physical science, something more than had been already achieved might fairly be demanded of it. British physicists had long been at a serious disadvantage in that they were without any means of readily ascertaining what was being done by their fellow-workers in other countries; with the multiplication of scientific literature the need of some periodical digest similar in character to the German Beiblätter was becom. ing year by year more urgent. To endeavour to meet this want was a duty which clearly devolved upon the Physical Society, and the Council anxiously considered the question whether the publication of monthly abstracts of physical papers appearing in foreign journals could be undertaken by ourselves.

The only serious objection to the enterprise was of a financial nature. The work, if it were to be carried out efficiently, would certainly necessitate an annual expenditure exceeding by some hundreds of pounds the total income of the Society. This could only be met by raising the amount of the annual subscrip. tion and composition fee, which, as I have mentioned, were un usually low. But it is a delicate and difficult matter to ask existing members of a society for increased subscriptions unless very excellent reasons can be shown for the demand. The Council therefore determined that they would publish a series of abstracts for one year at least before taking any steps to provide additional income, defraying the cost from cash in hand and, i need should arise, drawing upon the invested capital. In this way it was hoped to convince members of the utility of the undertaking which they were to be called upon to support.

I need not remind you of the highly satisfactory result of the experiment. The work of the able and assiduous body of abstractors whose names appear on the cover of our Proceedings was on all sides cordially approved, and at a special genera meeting, held in 1896 , a resolution submitted to the Society for increasing the subscription to two guineas per annum was passed almost, if not quite, unanimously. The number of those who in consequence of this increase have resigned their membership has been unexpectedly small, while on the other hand many of the life members have, in response to the invitation issued to them, voluntarily contributed an additional fifteen guineas to the funds of the Society, in recognition of the fact that they are now in enjoyment of greater and more costly advantages than were contemplated at the time when they paid their very moderate composition fees. To such as have not yet responded I venture to repeat the invitation.

Although the abstracts were actually published for two years before the increased subscriptions began to come in, the whole cost was met out of uninvested cash, supplemented by grants liberally made by the British Association and the Royal Society, and it was never found necessary to draw anything at all from the reserve fund. I wish to emphasise this fact because the abundant caution properly exercised by the Council in entering upon a new and uncertain enterprise appears to have led to a very general impression that the Society had outrun its means and was on the verge of bankruptcy, whereas in truth it was never in a more prosperous financial condition than it is at present.

On October 26, I 894 , the Society met for the first time in this room. Although the privileges so generously accorded to us by the authorities at South Kensington were highly valued, it was nevertheless deemed advisable that we should leave the home of our youth and seek a footing in Burlington House, the 